1. MBBS, DMRD

SMO

Department of Radiology

Social Security Hospital, Lahore.

2. MBBS, M.Phil. (Anatomy)

Assistant Professor

Department of Anatomy

Faisalabad Medical University,

Faisalabad.

3. M.Phil. (Anatomy)

Professor

Department of Anatomy

Nawaz Medical College Gujarat.

4. MD (Cuba)

Lecturer

Department of Anatomy

Sargodha Medical College,

Sargodha.

5. MBBS, M.Phil, Ph.D.

Professor \& Head

Department of Anatomy Independent Medical College

Faisalabad.

Correspondence Address:

Dr. Muhammad Adil Riaz

House No. 227, Block H1,

Sabzazar Lahore.

adilriaz227@gmail.com

Article received on:

03/10/2018

Accepted for publication:

20/02/2019

Received after proof reading:

$28 / 08 / 2019$

\section{FREQUENCY OF EPIDURAL HEMATOMA IN DIFFERENT AGES DUE TO ROAD TRAFFIC ACCIDENTS ON COMPUTED TOMOGRAPHY SCAN BRAIN.}

\begin{abstract}
Muhammad Adil Riaz', Anwaar Hussain², Habib ur Rehman³, Muhammad Aaqib Riaz', Irfan Ahmed Mughal ${ }^{5}$

ABSTRACT: Road traffic accidents are quite common in developing countries like Pakistan and mainly affect middle aged men. Objectives: To determine the frequency of epidural hematoma in different ages due to road traffic accidents on Computed Tomography scan brain. Study Design: Cross-sectional descriptive study. Setting: Emergency Radiology Department, Lahore General Hospital, Lahore. Period: August 2017 to November 2017. Material \& Methods: One hundred fifteen patients were selected who visited to emergency due to road traffic accidents. The individuals with head injury bearing hematoma were included. Axial computed tomography scan brain without contrast was performed. The frequency of epidural hematoma in different ages was determined. Result: Total one hundred fifteen patients were enrolled in the study; epidural hematomas were $49(42.60 \%)$ while no epidural hematomas were $66(57.39 \%)$. Out of 49 epidural hematoma cases males were $38(77.55 \%)$ and females were $11(22.45 \%)$ with a mean age of 19 years with a range of 2-55 \pm 9.59 years. All the individuals with head injury were categorized into three groups. The frequency of epidural hematoma in different ages was $75.51 \%$ (15-44 years) followed by $20.40 \%$ (<14years) and then $4.08 \%$ in (>45years). Conclusion: It was concluded from this study that epidural hematoma determined by computed tomography scan brain is more frequent in middle age.
\end{abstract}

Key words: $\quad$ Age Related Head Injury, Brain Disability, Epidural Hematoma, Head Trauma, Road Traffic Accidents.

Article Citation: Riaz MA, Hussain A, Habib ur Rehman, Riaz MA, Mughal IA. Frequency of Epidural hematoma in different ages due to road traffic accidents on Computed Tomography scan brain. Professional Med J 2019; 26(9):15761579. DOI: 10.29309/TPMJ/2019.26.09.4031

\section{INTRODUCTION}

Head injuries are more common in developing countries like Pakistan. Many neurological problems are caused by traumatic head injuries. ${ }^{1}$ In the United States annually 403 per 100,000 cases visits emergency due to road traffic accidents that leads to head trauma. ${ }^{2}$ In Pakistan, mortality rate due to head injury is reported about $15 \% .^{3}$ Traumatic skull injuries adversely affect the physical, mental and emotional health of individuals that ultimately enhance the socioeconomic problems. The effects that occurs after closed head injuries are very miserable and traumatic among patients who reach the hospital in living condition. ${ }^{4,5}$ Head injuries due to external trauma disturb the normal structure of cranium. Head injuries are classified as penetrating and closed. In penetrating injury, the skull is broken but it remains intact in closed injury. Accumulation of blood occurs due to head injuries forming hematoma at different locations. ${ }^{6}$ Epidural hematoma is the presence of collected blood between skull and outer Dura layer and associated with skull fracture mostly. CT scan is considered as one of the best imaging investigation modality in head injury patients and due to skull fracture, The patients presented with signs of raised intracranial pressure and internal bleeding are selected for CT scan.,

The purpose of this study was to identify the cases of epidural hematoma in different ages due to motor vehicle accidents that come in emergency diagnosed by CT scan brain and to treat them quickly to reduce morbidity and mortality. So in this way we can lower the disease level among the population. 


\section{METHODS}

This was Descriptive cross sectional study carried out in emergency department, Lahore General Hospital, Lahore. 115 cases of head injury due to road traffic accidents were selected for this study. Sample technique was simple random sampling. CT scan brain without contrast of all these patients was performed. Multi slice CT scan machine was used after taking informed verbal consent, demographic details and CT brain findings were compiled in sheet. Analysis of collected data was done with the Excel software and SPSS 22.No information regarding patient was published. The quantitative and qualitative variables were presented in the form of mean, standard deviation and charts.

\section{Inclusion Criteria}

All patients of both genders of all ages with closed head injury from road traffic accidents.

\section{Exclusion Criteria}

All patients without head injury and patients with bleeding disorders.

\section{RESULTS}

Total 115 patients were enrolled in the study; epidural hematoma was in 49 (42.60\%) while no epidural hematoma was in $66(57.39 \%)$ cases. Out of 49 epidural hematoma cases males were $38(77.55 \%)$ and females were 11 (22.45\%) with a mean age of 19 years with a range of 2-55 \pm 9.59 years. (Table I). All the individuals with head injury were categorized into three groups. Epidural hematomas in group I, less than 14 years were $10(20.40 \%)$, group II, 15 to 44 years were $37(75.51 \%)$ and group III, above 45 were 02(4.08\%). (Table-II)

\begin{tabular}{|l|c|c|}
\hline \multicolumn{1}{|c|}{ Gender } & Frequency & Percent \\
\hline Female & 11 & 22.45 \\
\hline Male & 38 & 77.55 \\
\hline Total & 49 & 100.0 \\
\hline
\end{tabular}

Table-I. Gender frequency of epidural hematoma

\begin{tabular}{|l|c|c|}
\hline Age Groups & Frequency & Percent \\
\hline$\leq 14$ & 10 & 20.40 \\
\hline $15-44$ & 37 & 75.51 \\
\hline$\geq 45$ & 02 & 4.08 \\
\hline Total & 49 & 100 \\
\hline
\end{tabular}

Table-II. Frequency of epidural hematoma in different age groups

\section{Frequency}

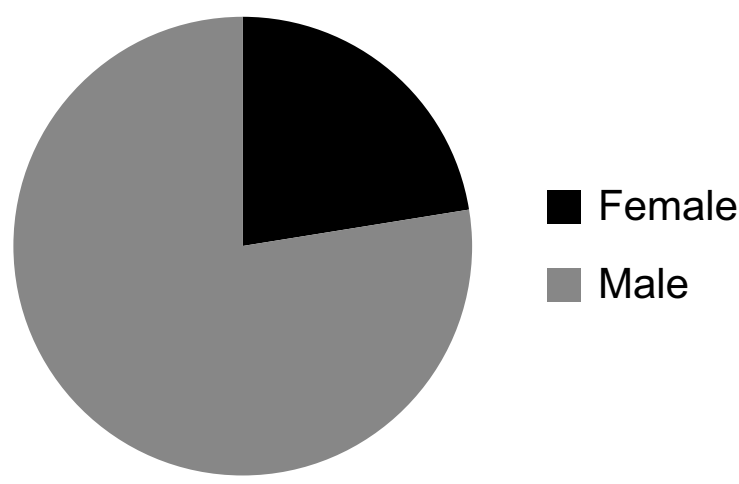

Graph-I. Gender frequency of epidural hematoma

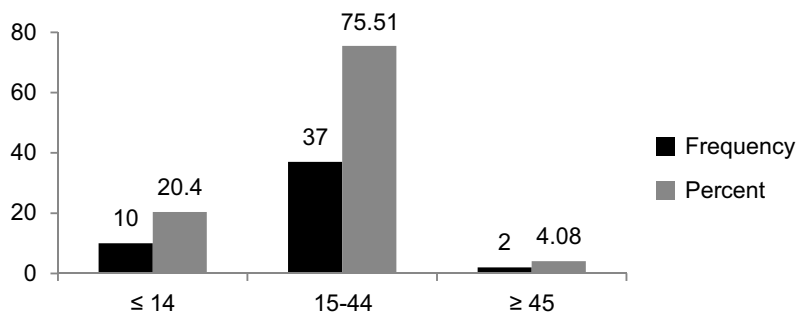

Graph-II. Frequency of epidural hematoma in different age groups

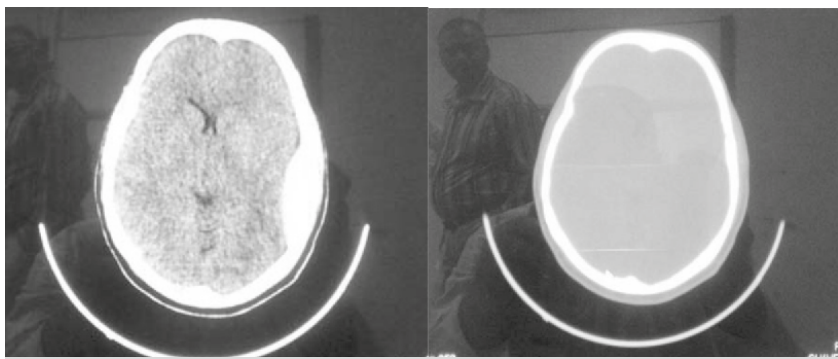

Figure-1. CT scan brain axial view showing epidural hematoma in left parietal lobe.

\section{DISCUSSION}

Road traffic accidents are major cause of traumatic brain injury and males are mainly affected victims of it as they are more involved in daily life activities. CT is one of the most important modality which is cheaper, rapid and widely available and an important diagnostic tool for various hematomas of brain. ${ }^{9,10}$

In our study we categorized all the individuals with head injuries into three age groups under 14 years group, 15 to 44 years and above 45 
years. Epidural hematoma in middle age group was mostly seen which was affected with head injuries, which is correlated with international studies. Gupta reported in $2011^{11}$ that males had higher incidence of head trauma as compared to females that are related to our results. 115 patients were enrolled in the study; who visited to the emergency department of Lahore General Hospital, Lahore, Pakistan and having head trauma the epidural hematomas were 49 (42.60\%) while no epidural hematomas were 66(57.39\%). Out of forty nine epidural hematoma cases males were $38(77.55 \%)$ and females were 11 (22.45\%) with a mean age of 19 years with a range of 2-55 \pm 9.59 years. Similar findings were observed by Gupta PK et al, 2011 ${ }^{11}$, Tabish A et al, 2008 ${ }^{12}$ and Khan MK et al, 2011. ${ }^{13}$

This is due to the fact that in our traditional culture and society the males of this age group involved in driving more as compared with females, thus they are more susceptible to the head trauma. In our study the frequency of epidural hematoma in different ages was $75.51 \%$ (15-44 years) followed by $20.40 \%$ (<14 years) and then $4.08 \%$ in (>45 years) that is comparable to the findings of Siddique $U$ et al $2016^{7}$, Sameer C, et $\mathrm{al}^{14}$ and Arfat $\mathrm{M}$ et al. ${ }^{15}$

IrieF et $a^{16} 2011$ narrated that $81 \%$ of epidural hematoma in young is traumatic and associated with skull fracture coinciding our study. Muhammad Sohail Umerani et all ${ }^{17} 2018$ also described prevalence of epidural hematoma in younger age group like our study and should be conscious in child with fracture skull.

\section{CONCLUSION}

It was concluded from this study that epidural hematoma determined by computed tomography scan brain is more frequent in middle age and males were affected more by the head injuries as compared to females.

Copyright@ 20 Feb, 2019.

\section{REFERENCES}

1. Umerani MS, Abbas A, Sharif S. Traumatic brain injuries: Experience from a tertiary care centre in Pakistan. Turkish Neurosurgery. 2013; 24(1):19-24.
2. Maas AIR, Stocchetti N, Bullock. Moderate and severe traumatic brain injury in adults; Lancet Neurol 2008; 7: 728-41.

3. Yousfani GM, Sohail S, Memon MU. Radiological appraisal of moderate to severe head injury. Medico legal Implications. JLUMHS 2010; 9(03):121-24.

4. Akanji AO, Akinola RA, Balogun BO, et al. Computerized Tomography scan and head injury: The experience in a tertiary hospital in Nigeria: A cross sectional study. Academic Journal 2015; 6(1):1-15.

5. Shankar $\mathrm{KH}$, et al. A clinical analysis of outcome in management of head injury in patients with highway road accidents. International Journal of Research in Medical Sciences 2016; 4(6): 2079-83.

6. RIAZ MA, RIAZ MA, TABUSSAM S. Frequency of Subdural Hematoma in Different Ages due to Motor Vehicle Mishaps on Computed Tomography Scan Brain. P JMHS OCT-DEC 2018; Vol. 12, (4): 1318-20

7. Siddique $\mathrm{U}$, Gul $\mathrm{H}$, et al. Intracranial hemorrhage in patients with head trauma on Computed Tomography Scan. Pakistan Journal of Radiology. 2016; 26(3):189197.

8. Ahsan Aurangzeb, et al. Frequency of extradural hematoma in patients with linear skull fracture. $J$ Ayub Med Coll Abbottabad. 2015; 27(2):314-317.

9. Yusuf AS, Odebode TO, Adeniran JO, Salaudeen AG, Adeleke NA, Alimi MF. Pattern and outcome of motorcyclists head injury in Ilorin, Nigeria. Nigerian Journal of Basic and Clinical Sciences. 2014; 11:8084.

10. Anuradha B, Pasam KL, Rani KR, Rani BS, Rao $\mathrm{KS}$. Role of CT in localising the injury to the particular intracranial compartment in patients with craniocerebral trauma. Journal of Evidence Based Medicine and Healthcare 2016; 3(91):4981-6.

11. Gupta PK, Krishna A, Dwivedi AN, Gupta K, Madhu $B$, Gouri G, et al. CT scan findings and outcomes of head injury patients: A cross sectional study. Journal of Pioneering Medical Sciences 2011; 1(3):78-82.

12. Yattoo GH, Tabish A. The profile of head injuries and traumatic brain injury deaths in Kashmir. Journal of Trauma Management \& Outcomes. 2008 Dec;2(1):5.

13. Khan MK, Hanif SA, Husain M, Huda MF, Sabri I. Pattern of non-fatal head injury in adult cases reported at JNMC Hospital, AMU, Aligarh. 2011; 33(1):21-23. 
14. Sameer C, Joshi H, Gaurav J, Kashmir S. Outcome of head injury patients based on computed tomography (CT) scan findings in a Tertiary Care Hospital:-A cross-sectional study. IJCMR. 2016; 3(2):610-612.

15. Arfat $M$, Zahiruddin $M$, Yadav $Y$, Brig $T$, Prabhakar V. Evaluation of epidemiological trends and severity of traumatic brain injury using multi-detector computed tomography scanner in Uttar Pradesh University of Medical Sciences Hospital. OMICS J Radiol. 2017; 6(254):2.
16. Irie F, LeBroique R, Kanardy N, Testworth $\mathrm{K}$ and Pollard C Epidemiology of traumatic epidural hematoma in young age J Trauma, 2011 Oct. 71(4): 847-50.

17. Muhammad Sohail Umerani, Asad Abbas, Fatima Aziz et al 2018. Paediatric extradural hematoma clinical assessment using kings outcome scale for chilhood head injury Asian neursurg. 2018 Vol.13, Issu. 3 P681684.

\begin{tabular}{|c|l|l|}
\hline \multicolumn{3}{|c}{ AUTHORSHIP AND CONTRIBUTION DECLARATION } \\
\hline Sr. \# & \multicolumn{1}{|c|}{ Author-s Full Name } & \multicolumn{1}{|c|}{ Contribution to the paper } \\
\hline 1 & Muhammad Adil Riaz & Principal Author \\
\hline 2 & Anwaar Hussain & Reviewer \\
3 & Habib ur Rehman & Reviewer \\
\hline 4 & Muhammad Aaqib Riaz & Reviewer \\
6 & Irfan Ahmed Mughal & Reviewer \\
\hline
\end{tabular}

